\title{
International
}

Journal of

DOI : 10.15740/HAS/IJPE/8.1/8-13

e ISSN-0976-7924 ■ Visit us : www.researchjournal.co.in

Research Paper

Volume 8 | Issue 1 | April, 2015 | 8-13

\section{Comparative study of different duration of warming-up on the selected physical fitness components of volleyball players}

\section{PUSHPALATA M. DESHMUKH}

Received : 28.01.2015; Revised : 20.02.2015; Accepted : 04.03.2015

Author for correspondence

PUSHPALATA M. DESHMUKH

Faculty of Physical Education, Shri

Shivaji College of Education,

AMRAVATI (M.S.) INDIA

\section{-ABSTRACT}

The purpose of the study was to determine the effect of warm-up of different duration on selected physical fitness components of volleyball players. The subjects were 20 male volleyball players of Inter collegiate volleyball tournament of Sant Gadge Baba, Amravati University, Amravati. The age of the subjects were ranged between 18 to 28 years. The data on selected criterion based on the test the research Scholar were the criterion measures selected for the purpose of the study were vertical jump in cms. Sit and Reach test in inches. Shuttle Run in seconds. Eye hand co-ordination in seconds and eye foot co-ordination in seconds. The test was administered consecutively for four days preceded by after no warms-up on the first day, 5 min. warm-up on the fourth day, respectively. The data pertaining to each of the selected physical components of volleyball players were examined by one way analysis of variance in order to determine the differences if any. The level of significance was set at 0.05 level of confidence. Significant difference found among the paired means in vertical jump (3.725) and sit and Reach test (3.921), but insignificance difference found in shuttle run (0.847), eye-hand co-ordination (0.512) and eye-foot co-ordination (1.046) selected different duration of warm-up i.e., without warm-up, 5 min warm-up, 10 min warm-up, $15 \mathrm{~min}$ warm-up. Hence, it is concluded that warm-up significantly affect on leg strength and flexibility.

- KEY WORDS : Warm-up, Physical fitness components, Volleyball

- HOW TO CITE THIS PAPER : Deshmukh, Pushpalata M. (2015). Comparative study of different duration of warming-up on the selected physical fitness components of volleyball players. Internat. $J$. Phy. Edu., 8 (1): 8-13. 